\title{
Ride through testing of variable speed drive due to voltage sag types (Types I, II and III)
}

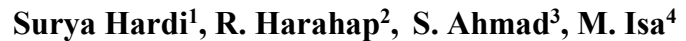 \\ 1,2,3 Department of Electrical Engineering, Universitas Sumatera Utara, Indonesia \\ ${ }^{4}$ School of Electrical Engineering, Universiti Malaysia Perlis, Malaysia
}

\begin{tabular}{l}
\hline Article Info \\
\hline Article history: \\
Received Oct 10, 2018 \\
Revised Nov 19, 2018 \\
Accepted Jan 19, 2019 \\
\hline
\end{tabular}

Keywords:

Ride through testing Susceptibility curve Variable speed drive Voltage sag types

\begin{abstract}
Variable speed drives (VSDs) are widely used in various applications mainly in process industry need constant rotational speed. It is developed from power electronic components thus saving energy in its operation. Unfortunately, it is susceptible against power quality problem for example voltage sags. The VSD may be disruption or drop out when it is supplied by voltage sags and it is determined by sag characteristics. This study is to investigate effect of voltage sags Types I, II and III on VSD through laboratory testing. The voltage sags characteristics are generated from voltage sag generator (Shaffner 2100 EMC). The effects are presented in susceptibility curves in disruption and drop out conditions. The curves resulted are evaluated by standard curve recommended. Test results show that voltage sag Type I cause the VSD disruption only, whereas two types sag other result in the VSD disruption and also drop out. Evaluation results explain a few test points are in operation area for disruption condition whereas test points for dropping out far below the threshold recommended. Hence the VSD has good quality to voltage sags.
\end{abstract}

Copyright (C) 2019 Institute of Advanced Engineering and Science. All rights reserved.

\section{Corresponding Author:}

Surya Hardi,

Department of Electrical Engineering, Universitas Sumatera Utara,

Dr. Mansyur street, Medan, Indonesia.

Email: surya.hardi@usu.ac.id

\section{INTRODUCTION}

Variable speed drives (VSDs) have been recognized as most susceptible equipment against voltage sags. The VSDs are developed by using power electronic components, therefore they are susceptible to voltage sags. Commonly, primary components of VSD are diode bridge rectifier, direct current (DC) link, inverter [1]. By reason energy saving, so it found in many applications such as industries, and commercial sectors. It function is to control motor speed to meet speed required. Motor with constant rotational speed is very required in industrial process such as industries: textile, glass, paper, steel plate, etc. Small change in speed can result in decreased product quality and consequence is economic loss. Susceptibilty of the equipment can be found via laboratory test and manufactur. But, generally manufacturers is not provide. Hence information about susceptibility of the VSD against voltage sags is crucial in order to can improve ride through capability of the VSD to voltage sags.

Response of VSD against voltage sag is different and it is depending on the voltage sag characteristics. The VSD may disruption for a moment and return to normal after end of sag. The VSD disrupts has effect on motor speed change. If voltage sag is deeper and longer result in the VSD may drop out so that connection between motor and the VSD interrupted. Some VSDs will quickly re-start, re-start with a specified time delay and some require a manual re-start. In some literatures VSD is also mentioned adjustable speed drive (ASD). 
Ride through capability of VSD caused by voltage sags have been studied by some researchers in [2-6]. In simulation model, affect of different capacitor dimensions on DC bus voltage magnitude and motor speed loss [2] was depicted in a curve for balanced and unbalanced voltage sags. Comparison of simulation and measurement for symmetrical voltage and single-phase voltage sags. Susceptibility curves were presented in various speed and torque for triple phase sags, double phase sags and single-phase sag, but the results did not evaluate by standard curve available [3]. Studied effects of unsymmetrical sag (Types: B, C and $\mathrm{D}$ ) on speed and torque have been carried out by simulation. The magnitudes depend on control method that used in VSD [4]. Investigation behavior of diodes rectifier current and sensitivity of VSD has been carried out through experimental test [5]. Diode behavior to conduct current to DC bus voltage may influence VSD performances was investigated. Result was analyzed under voltage sags of Type A and Type C. Investigation susceptibilty of VSD has been reported also in [6]. The results were presented in sensitive curve for drop out and evaluated with SEMI F47 curve.

This study is to investigate ride through of VSD caused by voltage sag Types I, II and III. Effect voltage sag types are presented in susceptibility curves for disruption and drop out conditions. The curves resulted are compared with immunity standard curve proposed.

\section{VOLTAGE SAG CLASSIFICATION AND SUSCEPTIBILITY STANDARD CURVE}

\subsection{Voltage sag classification}

Voltage sag is reduced voltage in root mean square (rms) from $90 \%$ down to $10 \%$ of nominal voltage that last from 0.5 cycles until one minute [7]. Duration sag is defined as begin voltage sag occurs until the end voltage sag. In some papers, voltage sags are also mentioned voltage dips. The voltage sags are one of most frequency disturbances in power system and it may consequence of short circuit fault and switching on of large motors. Magnitude and duration are main characteristics of voltage sags. Another characteristics are symmetrical, unsymmetrical, phase shift, point on wave of sag initiation, etc. The characteristics influenced on performance of equipment.

Some authors classify voltage sags into four types i.e. A, B, C and D [8]. Voltage sags can be also categorized in seven types namely types A, B, C, D, E, F and G [9]. These categorizations based on different sag magnitude for each phases and phase angle shift. More simple classification was documented in [10], [11] becomes three types which are Type I, Type II and Type III and displayed such as in Figure 1. Symmetrical sag is represented by Type III whereas Types I and II represent unsymmetrical voltage sags.

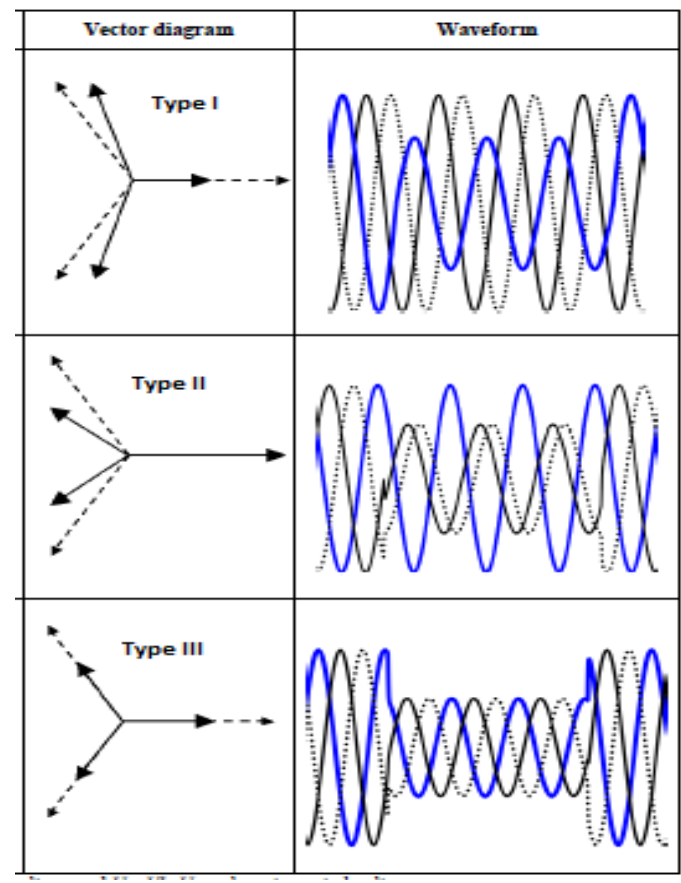

Figure 1. Voltage sag types 


\subsection{Susceptibility of standard curves}

Susceptibility of the drive against voltage sags is commonly presented in the form voltage tolerance curve or susceptibility curve. ITIC, information technology industry council power is curve which presents susceptibility of equipment to voltage disturbance [12]. SEMI F47 is the first time proposes susceptibility specific curve to voltage sags [13]. The curve has been used by some researchers among of found in [3, 5]. ITIC and SEMI F47 is depicted jointly as shown in Figure 2. Last susceptibility curves for three phase load against voltage sags Types I, II and III are proposed in [11]. Voltage sag Type I and Type II have similar shape template whereas Type III is different.

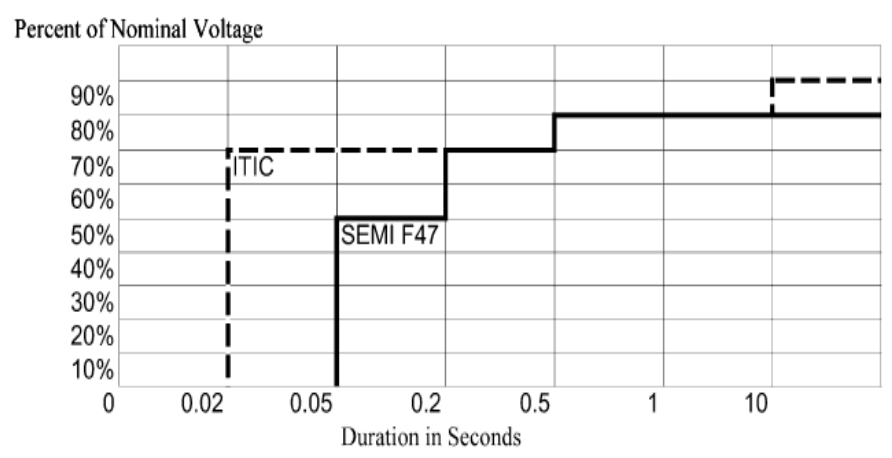

Figure 2. ITIC and SEMI F47 curves

\section{TESTING OF VARIABLE SPEED DRIVE}

A three phase VSD with rated power of $1.5 \mathrm{~kW}$, voltage of $415 \mathrm{~V}$, operating frequency of $50 / 60 \mathrm{~Hz}$ and $1.1 \mathrm{~kW}$ induction motor as load. Laboratory testing was carried out in Universiti Malaysia Perlis (UniMAP). Photograph of an VSD testing installation such as in Figure 3 which apparatus other are personal computer (PC) used for adjusting characteristic voltage sag desired and power quality analyzer (PQA) to observe voltage sag variation.

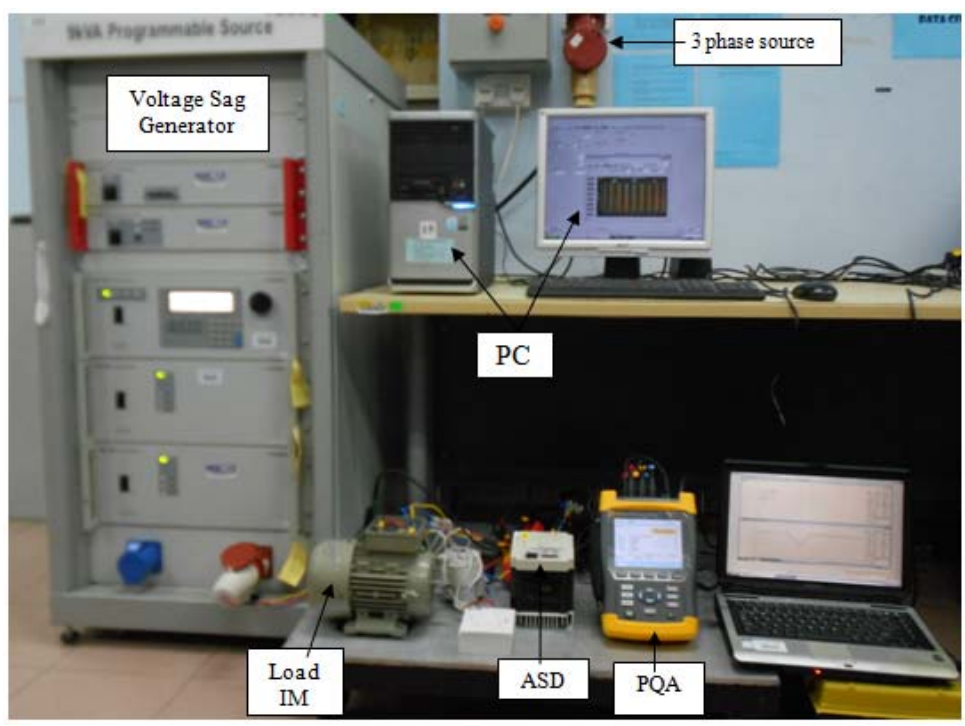

Figure 3. Photograph of VSD testing 
The VSD get supply from voltage sag generator (VSG) Shaffner 2100 EMC. Testing is started from voltage sags of $70 \%$ until $0 \%$ of nominal voltage and reduced by multiples of $2.5 \%$. Sag duration was set beginning from 20 milliseconds (ms) and until $1000 \mathrm{~ms}$ with additional time of $10 \mathrm{~ms}$. VSD responses is recorded, there are three conditions may be occur when the VSD is supplied by voltage sags viz. There is no effect, it means the VSD still normal operation. A disruption, it means connection motor with VSD is disconnecting for a moment, it is indicated by the VSD indicator lamp is off and VSD can restart fastly if the voltage returns to normal. A drop out is indicated by connection between the VSD and motor interrupted, then motor speeds slow down until stop and need manually restart to operate. Testing procedure is depicted by a flow chart as shown in Figure 4.

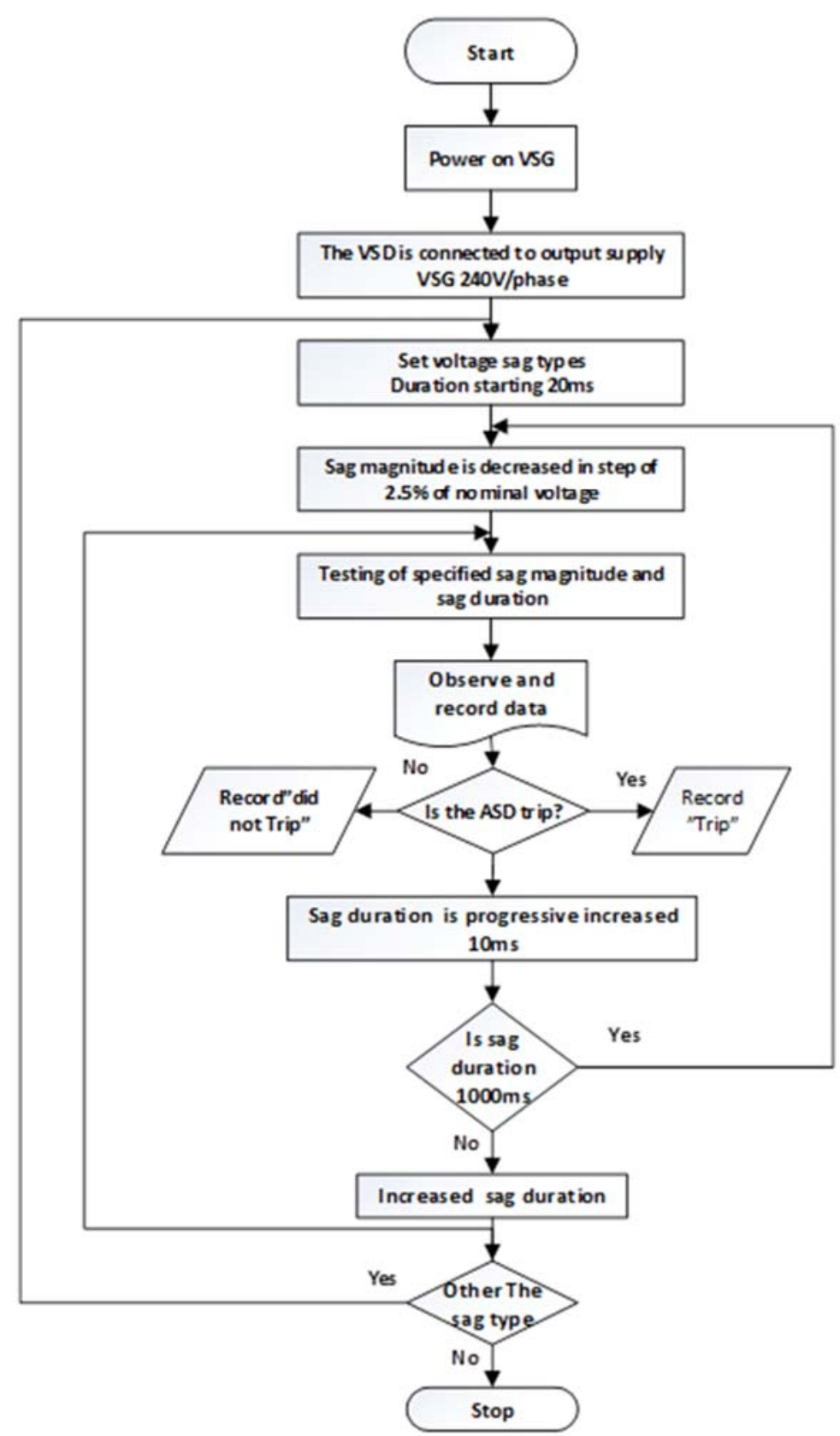

Figure 4. Flow chart for VSD testing 


\section{RESULTS AND DISCUSSION}

This part discuses testing results of three type voltage sags (Types I, II and III) on the VSD in disruption condition and drop out. To investigate, data recorded (disruption and drop out) are plotted by green and red lines within template of susceptibility curve recomended.

\subsection{Effect of voltage sag Type I}

Susceptibility curve caused by voltage sag Type I is displayed in Figure 5. The voltage sag causes the VSD disruption only. In voltage sag type I, one phase only voltage drops and two phases magnitude other do not change. This has effect on diode behaviors to conduct current to charge dc bus capacitor, as described in [5]. During sag, diodes rectifier in other two phase are forward biased so they will charge the capacitors. The VSD starts for disruption with duration of $80 \mathrm{~ms}$ and $57 \%$ voltage sag. Those values are threshold values for duration and magnitude of sags, respectively. It can be seen that curve lines in operation area from duration of $80 \mathrm{~ms}$ until $200 \mathrm{~ms}$. It means, if the VSD was supplied by voltage sags in ranges $57.5 \%$ to $50 \%$ of nominal voltage, it may disruption with duration in ranges $80 \mathrm{~ms}$ to $200 \mathrm{~ms}$.

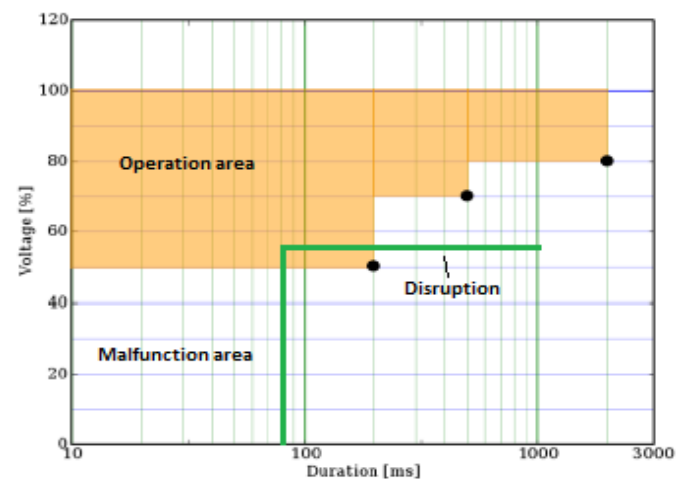

Figure 5. Susceptibility curve caused by Type I

\subsection{Effect of voltage sag Type II}

ASD was subjected to voltage sags are displayed in Figure 6. Type II depicts two phases voltage drop and phase angle shift, while one phase voltage other is not change. It can cause the VSD disruption and drop out also. Magnitude and duration sags required to drop out are deeper and longer than disruption. This is corresponding to [4], stated that most the equipment will trip when it is supplied by lower magnitude and long duration. The VSD starts to disrupt at $60 \%$ of rated voltage and $80 \mathrm{~ms}$ duration whereas to drop out at voltage of $27.5 \%$ and duration of $230 \mathrm{~ms}$. Drops out curve resulted is well below operation area, this can explain that the VSD has good immunity against sag Type II to drop out.

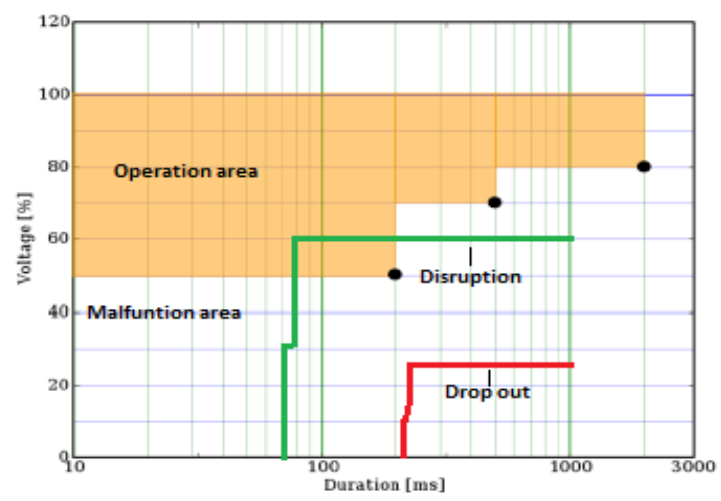

Figure 6. Susceptibility curve caused by Type II 


\subsection{Effect of voltage sag Type III}

Susceptibility curves caused by voltage sags Type III have been plotted shuch as in Figure 7 . The Figure shows the VSD in disruption and drop out conditions. The VSD is more susceptible than two type sags other. This is because voltage sags Type III results in drop all three phases. The consequences diodes bridge rectifiers were reverse biased so there is no charging on dc bus capacitance during voltage sag. It starts to disrupt and drop out while was supplied by $70 \%$ and $60 \%$ of nominal voltage, respectively. The fastest duration that causes the VSD disruption and drop out is $80 \mathrm{~ms}$ and $210 \mathrm{~ms}$, respectively. Nevertheless, the ASD is categorized has high immunity class to drop out.

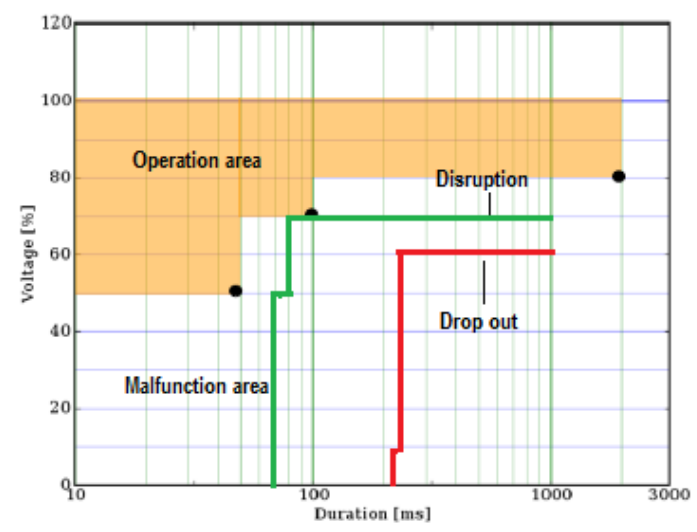

Figure 7. Susceptibility curve caused by Type III

\section{CONCLUSION}

Testing has been carried out on ASD due to voltage sag Types I, II and III. The results are presented in two condition viz. susceptibility curves in disruption and drop out. Susceptibility of the VSD for the conditions are depending on types of voltage sags applied. Voltage sags required for the VSD disruption are $57.5 \%, 60 \%$ and $70 \%$ of nominal voltage for Types I, II and Type III, respectively. Immunity level of the VSD is lowest when it was supplied voltage sags Type III and it drops out at voltage sag of $60 \%$ and duration of $230 \mathrm{~ms}$. Voltage sag Type I causes the VSD disruption only at duration of $80 \mathrm{~ms}$. Eventhough a few testing points are in operation area, it causes disruption only, therefore the VSD has high immunity to voltage sags. The susceptibility curves show almost similar pattern.

\section{ACKNOWLEDGEMENTS} this research.

We are very grateful to Universiti Malaysia Perlis (UniMAP) who provided laboratory facility for

\section{REFERENCES}

[1] M.H. Rashid "Power Electronics Circuits, Devices and Application". $4^{\text {rd }}$ Edition, 2014. Prentice Hall, 2014.

[2] M.H.J Bollen and L. D. Zhang., "Analysis of Voltage Tolerance of AC Adjustable-Speed Drives for Three-Phase Balanced and Unbalanced Sags," IEEE Transactions on Industry Applications, vol. 36(3), pp. 904-910, 2000.

[3] S.Z. Djokic et al, "Sensitivity of AC Adjustable Speed Drives to Voltage Sags and Short Interruptions," IEEE transactions on Power Delivery, pp: 494-505, 2005.

[4] M.P Petronijević, et al., "Comparative study of Unsymmetrical Voltage Sag Effects on Adjustable Speed Induction Motor Drives," IET Electric Power Applications, pp. 432-442, 2010.

[5] S. Hardi, et al., "Adjustable Speed Drives Response to Voltage Sags," Applied Mechanics and Materials, vol. 367, pp. 171-180, 2013.

[6] L.E. Weldemariam, et al.,"Experimental Investigation on the Sensitivity of an Industrial Process to Voltage Sags," Proceeding of IEEE Eindhoven Power Tech, pp. 1-6, 2015.

[7] M.H.J. Bollen, "Understanding Power Quality Problems: Voltage sag and Interruption," IEEE Power engineering Series, New York, 2000.

[8] E. Styvaktais, et al., "Classification of Power System Events: Voltage Dips," Harmonics and Quality of Power. IEEE Proceedings. 9th International Conference, vol. 2, pp: 745-749, 2000. 
[9] Pedra J. Felipe Córcoles, and Suelves F.J., "Effects of Balanced and Unbalanced Voltage Sags on on VSI-FED Adjustable Speed Drives,". IEEE Transactions on Power Delivery, vol. 20, no. 1, pp. 224-233, 2005.

[10] M.H.J. Bollen, et al., "Voltage Dips Immunity of Equipment in Installation (Messages to stake holder),". Harmonics and Power Quality of Power (ICHQP), IEEE 15th International Conference, pp. 915-919, 2012.

[11] IEEE P1668 Testing for End-Use Electrical Equipment Rated Less than 1000 V. 2014.

[12] G. T Heydt, et al., "Power Aceptabilty,". IEEE Power Enggineering Review, pp. 12-15, 2001.

[13] SEMI F47-0200, "Specification for Semiconductor Processing Equipment Voltage Sag Immunity," Available from: http://www.semi.org/pubs/semipubs.nsf.

\section{BIOGRAPHIES OF AUTHORS}
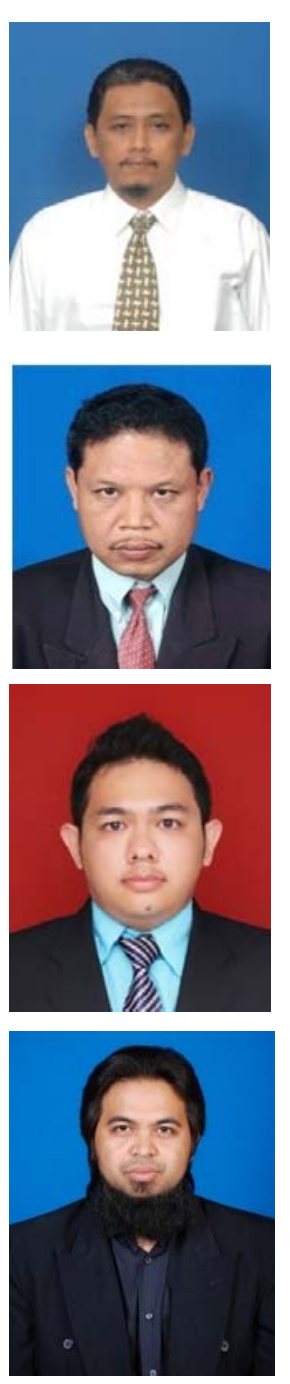

Surya Hardi received the Bachelor degree from Universitas Sumatera Utara (USU), Master degree from Institute of Bandung Technology (ITB) and Ph.D degree from Universiti Malaysia Perlis (UniMAP). His research interest includes: power quality, protection system and power system grounding, and high voltage engineering. He is a senior lecturer at Department of Electrical Engineering, USU, Indonesia.

Raja Harahap received the Bachelor degree from Universitas Islam Sumatera Utara (UISU), Master degree from Institute of Bandung Technology (ITB). He is a senior lecturer at Department of electrical engineering, USU, Indonesia. His research interest includes; power electronic and machines.

Said Ahmad, graduated Bachelor degree from Universitas Islam Sumatera Utara (UISU). He is a master student at Universitas Sumatera Utara (USU) and works as Staff PT. INALUMIndonesia. His research interest are power electronic drive and power quality.

Muzamir Isa received D.Sc (Tech.)(High Voltage Eng.) (Aalto University, Finland) M.Eng. (Elect. Eng) (KUiTTHO \& FH Koln, Germany, B.Eng. (Hons.) (Electrical -Power) (UTM). He is a Associate Profesor at School of electrical engineering, UniMAP, Malaysia. 